\title{
Ueber die Knollen von Cyclamen europaeum und das Cyclamilı.
}

Diese Knollen enthalten einen gährungsfähigen Zuckerstoff, Stärkniehl, Gummi und eine scharfe, reizendo und giftige Substanz. Der ausgepresste Saft derselben ist sauer und besitzt einen ausserordentlich scharfen und zusammenzichenden Geschmack. M. S. de Luca hat das giftige Princip isolirt und seine Eigenschaften untersucht. Er nennt es Cyclamin.

Um es darzustellen, macerirt man 4 Kilogrm. gut gewaschener und zerschnittener Knollen mit 4 Litres Alkohol 6 Wochen lang an einem dunkeln Orte, giesst die Flüssigkeit ab, zerquetscht die Knollenstïcke in cinem Mörser und macerirt abermals 1 Monat lang mit 3 Litres Alkohol. Nachdem die Flüssigkeit durch Abpressen entfernt, macerirt man nochmals 20 Tage hindurch mit 2 Litres 'Alkohol und presst ab. Die vereinigten Auszüge werden filtrirt, der grösste Theil des Alkohols abdestillirt, der concentrirte Auszug, vor Licht geschiitzt, im Wasserbade zur Trockne abgedampft und der Rückstand durch kalten Allkohol erschöpft.

Die vereinigten und filtrirten alkoholischen Lösungen werden 40 Tage lang der freiwilligen Verdunstung uiberlassen, nach welcher Zeit sich auf dem Boden des Gefins. ses eine weisse, amorphe Masse in Form kleiner Con. glomerate ausgeschieden hat. Man wäscht sie wiederholt; mit kaltem und löst sie in hoissem Alkohol, aus welcher: Lösung das Cyclamin beim Erkalten sich in denselben amorphen Conglomeraten ausscheidet und unter Lichtabschluss getrocknet wird.

Das Cyclamin stellt eine amorphe, weisse, geruchlose, undurchsichtige, zerbrechliche und leichte Substan:z dar, die sich gegen Reagentien neutral verhält. In Berührung mit feuchter Luft vermehrt sich sein Volumen durch Absorption einer grossen Mienge Wasser. Durch das Licht wird es gebräunt. Mit wenig kaltem Wasser befeuchtet, wird es durchscheinend und erhält das $\Lambda \mathrm{n}$ : sehen einer schleimigen Gallerte. Löst sich leicht in kaltem Wasser, ebenso in grosser Menge in Alkohol ur.ter geringer Temperaturerhöhung. In der Wärme löst es sich ohne Zersetzung in Glycerin, absolutem Alkohol, in den Alkalien; unlöslich dagegen ist es in Aether, Schwofelkohlenstoff, Chloroform und in den ätherischen Uelen. 
Seine wässerige Lösung erzeugt durch Rühren einen Schaum wie Seifenwasser, und hat die Eigenschaft, bei $-60-70^{0}$ wie Eiweiss zu coaguliren. Durch das Frkalten und 2-3 Tage Ruhe löst sich das Coagulum wieder in dem Wasser auf, und kann durch Wärme von Nouem zum Gerinnen gebracht werden. Auf dem Platinblech erhitzt, binterlïisst es eine voluminöse Koble, die ohne Rü̈ckstand verbrennt. Seine wässerige Lösung färbt sich nicht durch Jod und kann nicht durch Hefe in Gährung gesetzt werden; sic absorbirt leicht Bromdümpfe, ohne sich dadurch zu fürben, wenn nicht das 33 rom im Uebermaass vorhanden ist; ähnlich wirkt darauf das Chlor. Dureh Einwirkung der Synaptase bei einer Wärme von $+30-35^{0}$ zersetzt es sich unter Bildung von Glycose. Essigsäure löst es kalt, und die Lösung gerinnt nicht durch Erwärmen; Salzsiiure löst es ebenfalls kalt und die Lösung gerinnt bei +800 unter 13ildung von Glycose. Concentrirte Schwefelsäure färbt das Cyclamin gelb und endlich violett, welche Fürbung durch Zusatz von vielem Wasser, unter Erzeugung eines weissen Nicderschlages, verschwindet. Quecksilberchlorid ist ohne alle Einwirkung auf die wässerige Lösung des Cyclamins, Gallussäure macht sie gerinnen.

Der Geschmack des Cyclamins ist eigenthümlich scharf und den Schlund reizend. Die Elementaranalyse ergab:

$$
\begin{array}{lr}
\text { C } & 54,55 \\
\text { If } & 9,11 .
\end{array}
$$

Auf den thierischen Organismus wirkt es giftig ein, ähnlich wie das Curara-(xift, nur minder heftig als dieses. Als wirksames Antidot hat sich das Brom erwicsen.

In Calabrien benutat man die Knollen zum Fangen der Fische in süssen Gewässern. Die Knollen werden zu diesem Behufe zu Brei zerquetscht und in einen dichten leinenen Beutel, bei heissem Wetter und klarem Ifimmel, in dic Mitte des Flusses gehiingt und dort der Saft aus dem Beutel godrïckt. Nach kurzor Zoit schwinmen die Fische an den Ufern oben auf und befinden sich in einer Art Erstarrung. (Journ. de Pharm, et de Chim. Juin 1857. p. 427 ff.)

Hendess.

\section{Bestimmung des Morphiumgehalts im 0pium.}

Nach Fordos zieht man nach und nach $15 \mathrm{Grm}$. Opium mit erneuerten Mengen Wasser aus, wozu im 